\title{
New guidelines for training in adult cardiovascular disease
}

\section{Guidelines}

\section{Adult cardiology}

GENERAL PROFESSIONAL TRAINING

Three years general medical training. Specialisation in cardiovascular medicine without an adequate period of general medical training is discouraged. Research experience may be appropriate before beginning higher specialist training.

\section{HIGHER SPECIALIST TRAINING}

The increasing need for cardiological expertise in the district general hospital (DGH) coupled with other factors such as the decreasing reliance on cardiac catheterisation have rendered the separate senior registrar training programmes for physiciancardiologists in the DGH and for cardiologists in the specialist centre inappropriate. They are now replaced by a single training programme for the spectrum of existing consultant posts in cardiovascular medicine and cardiology.

Overlap of and variation in the components of the training programme must be allowed in the interests of flexibility and in order to cater for the talented individual with unorthodox experience and approaches. For example, obligatory cardiology and general (internal) medicine $(\mathrm{G}(\mathrm{I}) \mathrm{M})$ training may be undertaken simultaneously provided that the overall amount of training is as specified below. The circumstances and requirements of individual departments and hospitals will be taken into account and, as usual, ad personam approval will be considered for special cases.

(i) Obligatory cardiology training - Of the four years required for specialist training, at least two years should be spent in active clinical participation as senior registrar in a specialist cardiac centre, including at least one year in a centre with cardiac surgery. During this time the specialist training should be based on clinical experience in general cardiology (inpatient and outpatient care), and should include training in cardiac catheterisation and angiography, echocardiography, ambulatory monitoring, cardiac pacemaking, exercise stress testing, nuclear cardiology, acute coronary care, and the care of patients before and after cardiac surgery.

(ii) Obligatory $G(I) M$ training-One year or its equivalent should be spent in a post approved for higher medical training in general medicine.

(iii) Fourth year-A further year of this higher medical training programme should not be spent undertaking service cardiology but should offer the opportunity for experience in one or more related fields which is of benefit to the trainee wishing to practise general and cardiovascular medicine, eg general medicine, hypertension, pharmacology, epidemiology, cardiac rehabilitation, cardiovascular research. Up to one year of this experience would be eligible for retrospective accreditation, whereas the obligatory training requirements listed in (i) and (ii) above would normally be after appointment as senior registrar.

(iv) The senior registrar training programme must include adequate opportunity for research.

(v) The senior registrar training must include a regular teaching commitment.

\section{Paediatric cardiology}

\section{GENERAL PROFESSIONAL TRAINING}

Should include six months neonatal paediatrics, six months in general paediatrics, and one year in adult or paediatric cardiology.

\section{HIGHER PROFESSIONAL TRAINING}

Obligatory experience: four years in approved training in paediatric and adult cardiology progressing towards full specialisation in paediatric cardiology.

Document JCHMT 5/84 (July 1984) 


\section{Comments}

The specialist advisory committee in cardiovascular disease has recently reviewed the guidelines for specialist training in cardiology. New guidelines have been drawn up over the last two years with the agreement of the British Cardiac Society and its council, the cardiology committee of the Royal College of Physicians, and the specialist advisory committee in general internal medicine. We here briefly outline the functions of the specialist advisory committee and summarise the reasons for the change.

\section{The JCHMT and the SAC}

The Joint Committee on Higher Medical Training (JCHMT) is responsible for formulating guidelines for training in the medical specialties, approving posts and training programmes, and granting accreditation. Posts are approved as suitable for specialist higher medical training by the Specialist Advisory Committee (SAC) after considering the reports of visitors and are periodically reviewed. On appointment to an approved senior registrar post an incumbent should apply to the Joint Committee, c/o The Royal College of Physicians, London, for enrolment in the relevant specialties, using forms available from postgraduate deans. Adequacy of general professional training and the possibility of retrospective recognition of accreditable specialist experience will then be assessed. After completion of the training programme of higher medical training, the senior registrar should apply to the Joint Committee for accreditation, using forms likewise available from postgraduate deans.

\section{Reasons for change}

The old guidelines recognised two different types of cardiologist-neatly, if invidiously, labelled as types $\mathrm{A}$ and $\mathrm{B}-$ the former in a specialist centre with car- diac catheter facilities and cardiac surgery, the latter in the district general hospital.

The practice of the specialty has changed considerably. Technological developments have brought much of modern diagnostic cardiology within the capabilities of the district general hospital, where the prevalence and nature of cardiac problems and the extent to which they have become amenable to treatment have brought a need for cardiological expertise. These same developments have generated a workload and subspecialisation in cardiology at regional centres which have tended to separate the specialty from general medicine. A byproduct has been loss of flexibility, with a mismatch between trained senior registrars and available consultant posts.

Present patterns of practice require the appointment of consultants with cardiological expertise to district general hospitals, where they must usually also act as general physicians. Cardiologists in regional centres must likewise be well versed in general medicine. Many cardiologist/physicians at district general hospitals now in fact retain cardiology sessions at their regional centre, while the extent to which the cardiologists at the regional centre practise general medicine and participate actively in cardiac investigation varies with local practice, preference, and seniority. The senior registrar should accordingly be trained for a spectrum of cardiological posts in which to develop his/her special interest as appropriate.

A H Henderson, Chairman

M C Petch, Secretary

(Specialist Advisory Committee) 